\title{
Effects of Two Types of Human Cells on Outgrowth of Human Glioma in Rats
}

\author{
Zahra ABDI ${ }^{1,2}$, Hossien ESKANDARY ${ }^{3,4}$, Seyed Noureddin NEMATOLLAHI-MAHANI ${ }^{1,3}$ \\ ${ }^{1}$ Afzalipour School of Medicine, Department of Anatomy, Kerman, Iran \\ ${ }^{2}$ University of Medical Sciences, Department of Anatomy, Kerman, Iran \\ ${ }^{3}$ Kerman University of Medical Sciences, Neuroscience Research Center, Institute of Neuropharmacology, Kerman, Iran \\ ${ }^{4}$ Afzal Research Institute (NGO), Kerman, Iran
}

\section{ABSTRACT}

AIM: Glioblastoma multiforme (GBM) is one of the malignant brain tumors that occur most frequently. Despite advances in therapy techniques, the cure of GBM is a major concern. Accordingly, there is a lot of interest in devising novel approaches, such as stem cell therapy, to treat patients with GBM. The aim of this study was to investigate the effects of human bone marrow stem (BMS) cells as well as human olfactory ensheathing cells (OECs) on the outgrowth of U87 glioma in rats.

MATERIAL and METHODS: OECs and BMS cells were obtained from volunteers. After verification of the stem cell type by flow cytometry and immunocytochemistry (ICC), cells were labeled and injected into human glioma-bearing rats. Magnetic resonance imaging (MRI), Hematoxylin and Eosin (H\&E), and Immunohistochemistry (IHC) were utilized to assess the properties of the groups.

RESULTS: We found extensive migration and homing of the OECs and BMS cells towards the tumor area. H\&E and IHC staining indicated that the grafted OECs survived and prevented the development of glioma. BMS cells supported proliferation and new vessel formation, and metastasis in glioma tissue.

CONCLUSION: OECs and BMS cells can pass the blood brain barrier and reach the glioma mass. Therefore, this approach can be a potentially powerful method for the delivery of therapeutic agents to malignant brain tumors. In addition, these cells may be genetically modified in order to specifically express tumor-suppressive factors.

KEYWORDS: Glioblastoma multiforme, Stem cell therapy, Histopathology

\section{INTRODUCTION}

$\checkmark$ lioblastoma (GBM) is one of the primary malignant brain tumors that occur most frequently. Nearly, all patients with GBM die within 12-15 months of the initial diagnosis $(3,7,25)$. Therapies are still limited due to the ability of the blood brain barrier (BBB) to prevent the crossing of a broad range of anti-cancer agents $(10,19)$. Therefore, the cure of GBM is a major concern. Accordingly, there is a lot of interest in devising novel approaches, such as stem cell therapy, to treat patients with $\operatorname{GBM}(10,12)$.
In early cell-therapy studies (in the treatment of cancer), Aboody et al. (2) showed significant migration of neural stem cells (NSCs) towards the tumor area. In line with this, types of stem cells, and especially mesenchymal stem cells (MSCs), that have been evaluated in several tumor models including breast, prostate, and ovarian cancer are used $(11,15,23)$. However, the data are not adequate and some are contradictory to each other.

Olfactory ensheathing cell (OEC) is a neural stem cell type of the glial family like astrocytes and Schwann cells (35). In the recent decade, several reports have provided evidence that 
OECs have high capacity of migration towards the damaged tissues of central nervous system (CNS) without tumorigenicity behavior $(14,18)$. Therefore, the aim was to investigate the effects of bone marrow stem (BMS) cells as well as olfactory ensheathing cells on the outgrowth of U87 glioma in rats.

\section{MATERIAL and METHODS}

This study was approved by the Ethical Commission of the Kerman University of Medical Sciences with Approval number $\mathrm{EC} / \mathrm{KNRC} / 86 / 23$.

\section{Culture of stem cells}

\section{BMSCs}

BMS cells were extracted by processing bone marrow aspirates from one healthy donor as described previously (4). Briefly, the bone marrow was aspirated from the posterior iliac crest. The sample was rinsed, centrifuged, and Buffy coat was cultured at $37^{\circ} \mathrm{C}$ and $5 \% \mathrm{CO}_{2}$ air atmosphere. 48 hours later, the cells were washed; culture medium was added and then changed every 3 days. After 15 days, adherent cells formed colonies and when the cells achieved suitable confluency, the harvested cells from 3 passages were used in the different studies.

\section{OECs}

During a pituitary tumor resection from a 34-year-old male, the olfactory bulb was obtained (computed tomography (CT) and magnetic resonance imaging (MRI) findings of the patient showed a huge suprasellar lesion and the neurosurgeon had to cut the right olfactory bulb for better and more accurate surgery of the tumor). After isolating the olfactory bulb, it was stored in a falcon containing sterile Hank's Balanced Salt Solution (HBSS) and antibiotic. The pia was removed and the olfactory bulb tissue was cut into small pieces. They were washed with HBSS and incubated for one hour at $37^{\circ} \mathrm{C}$ in a mixture of trypsin/DNase in HBSS. The tissue fragments were dissociated mechanically. Afterward, the dissociated cells were washed with phosphate buffered saline (PBS) and seeded onto culture flasks with complete medium. After 5 days, the flasks were washed with PBS for removal of non-adherent cells, and culture medium was added. The harvested cells were detached with a mixture of trypsin/ Ethylenediaminetetraacetic acid (EDTA) and used in the study process.

\section{Characterization of cells}

\section{Flow cytometry of BMSCs}

The procedure surface of marker analysis was obtained from Seyedi et al. (37). Briefly, the CD34, CD44, CD45, CD73, CD90, CD105, CD117, and OC4 markers were analyzed using fluorescence-activated cell sorting (FACS) in the BD Bioscience Flow cytometer.

\section{Osteogenic and Adipogenic differentiation of BMSCs}

Osteogenic and adipogenic differentiation methods were described elsewhere (21). Briefly, $2-3 \times 10^{4}$ cells $/ \mathrm{cm}^{2}$ were seeded and fed with osteogenic and adipogenic inducing medium for 21 days. After 21 days, the Alizarin red and Oilred staining process was performed in order to detect the Calcium-phosphate precipitates and fat droplets respectively.

\section{Immunocytochemistry (ICC) of OECs}

Immunocytochemistry procedure of the OECs was obtained from Salehinejad et al. (36). Briefly, cultured cells were fixated, washed, incubated with primary antibodies, including mouse monoclonal anti-S $S_{100} \beta$ (Chemicon) and mouse anti-p75 (Abcam, USA). The slides were washed and incubated with fluorescent secondary antibodies Alexa 594 and Alexa 488. Afterwards, slides were stained with Hoechst and mounted.

\section{Cells labeling with $\mathbf{P K H}_{67}$}

$\mathrm{PKH}$ (a membrane- binding fluorescent dye) was employed to label bone marrow stem cells (BMSCs) and OECs. The procedure for labeling was described previously (1). Briefly, the cells were detached, centrifuged, and counted. Afterwards, cells were rinsed and suspended in Diluent C. Immediately, the staining mixture (Diluent $\mathrm{C}+\mathrm{PKH}_{67}$ ) was added to the cells. After 3-5 minutes, $400 \mu \mathrm{l}$ fetal bovine serum (FBS) was added to stop the reaction. The cells were centrifuged, washed, and seeded in flasks.

\section{Culture and labeling of U87 Cells}

U87 MG cells were cultured at $37^{\circ} \mathrm{C}$ and $5 \% \mathrm{CO}_{2}$. Afterwards, cells achieved $80-90 \%$ confluency and were detached by trypsin/EDTA. U87 cells were centrifuged, counted, and used for the experimental procedure. To use the U87 cells in the experimental procedure, they were labeled with $\mathrm{PKH}_{26}$ dye and the aforementioned labeling process (1).

\section{Induction of tumor}

In this study, 28 male Sprague-Dawley rats weighing 200-250 $\mathrm{g}$ were chosen. They were kept under normal conditions. They were randomly allocated into four groups (PBS, Tumor, BMSC, and $\mathrm{OEC}$ ) of 7 rats. The implantation procedure of U87$\mathrm{PKH}^{+}{ }_{26}$ cells was described previously (1). Briefly, rats were anesthetized and fixed in a stereotaxic frame. The scalp was incised and a hole was drilled in the skull. Then, the needle was inserted into the right frontal lobe. For three of the groups (except the PBS group), $10 \mu \mathrm{l}$ of cell suspension $\left(10^{6}\right.$ cells) was injected. The same process was done for PBS group, but only $10 \mu$ PBS was infused.

\section{Determination of tumor by MRI}

Ten days after tumor induction, MRI was performed on the rats as described previously (1). Briefly, the animals were anesthetized and positioned head-up in the coil of a 1.5-Tesla machine and both T1- and T2-weighted spin-echo images were obtained.

\section{Transplantation of $\mathrm{PKH}_{67}^{+}$cells}

The $\mathrm{PKH}^{+}{ }_{67}$ cells implantation process was described previously (1). Briefly, on the $10^{\text {th }}$ day of the experiment, rats were anesthetized; the skin and muscles of the thorax were incised in the left fifth intercostal space. Afterwards, $2 \times 10^{6}$ $\mathrm{PKH}_{67}{ }^{+}$cells $(100 \mu \mathrm{l})$ were infused by an insulin syringe into the left ventricle of the heart of the therapy group rats (BMSC and OEC). 


\section{Hematoxylin-Eosin (H\&E) and Immunohistochemical (IHC) staining}

On the $17^{\text {th }}$ day of the experiment, all animals were anesthetized and perfused as described previously (1). The brains were postfixed with the fixing/embedding, sectioning, and mounting process. Following deparaffinization/rehydration, some of the slides were stained with $\mathrm{H} \& \mathrm{E}$ and some of sections were used for the IHC staining process. For IHC staining, they were incubated with primary antibodies, including PECAM-1 monoclonal mouse anti-rat CD31, monoclonal mouse anti-human Nestin, monoclonal mouse anti-human Ki-67, and monoclonal mouse anti-human antibody glial fibrillary acidic protein (GFAP). Then, the slides were incubated with secondary antibodies; streptavidin/biotinylated peroxidase complex counterstained and mounted. The proportion of CD31 , Nestin, Ki-67, and GFAP positive cells, and the percentage of stained cells in 200 cells, were calculated.

For detecting $\mathrm{PKH}^{+}$cells in the animals, three brains from each tumor-bearing group were immediately frozen. Cryostatgenerated slides were mounted and examined with a fluorescence microscope equipped with a digital camera.

\section{Calculation of tumor volume}

For this purpose, serial sections of each sample were prepared. The sections were $3 \mu \mathrm{m}$ and the interval between the sections was $20 \mu \mathrm{m}$ throughout the length of the tumor. These stained sections (with H\&E) were photographed using a light microscope equipped with a digital camera. Serial images of each sample were used for calculating the tumor area (A) using the Analysis software. The Analysis software allows the reader to draw a line around the perimeter of the tumor. Each of these images, the tumor sectional areas were measured and the volume $(\mathrm{V})$ was calculated by the following formula:

$V_{(m m)}^{3}=\left(A_{1}+A_{2}+A_{3}+\ldots+A_{n}\right) \times 20 n+3 n$.

Here, " $n$ " is the number of sections containing tumor.

\section{Statistical Analysis}

Data are expressed as mean \pm SEM and the KolmogorovSmirnov test was used for measurement distribution of the data. Data were analyzed with the one-way ANOVA test (SPSS version 21) and a $p$ value $<0.05$ was considered significant.

\section{RESULTS}

\section{Characterization of cells}

\section{BMSCs}

Cultured BMS cells contained an analogous population of spindle-shaped cells (Figure 1A). Flow cytometry analysis revealed the expression of MSCs defined markers such as CD44 (54\%), CD73 (82\%), CD105 (80\%), CD90 (83.33\%), and negative expression of hematopoietic-specific markers CD34 (4.5\%), CD117 (12.75\%) and CD45 (5\%). It has been shown that BMS cells express OCT4 (19\%) (Figure 1B).
Under osteogenic induction medium, Alizarin Red staining revealed an extension of mineralization with detectable bone nodules in cells (Figure 1C). Interestingly, when BMS cells grew under adipogenic conditions, they showed fat droplets after staining by using oil-red $O$ dye (Figure 1D).

\section{OECs}

In this study, OECs were successfully derived from the olfactory bulb, and the majority of OECs were spindle-shaped with a large nucleus. IHC data showed strong staining for $S_{100} \beta$ and p75NGFR (Figure 2A-G).

\section{MRI}

MRI analysis revealed that a tumor mass was formed in glioma-bearing rats compared with control rats. On coronal T1-W images, the spot was iso- to hypo-intense in the tumor groups. Moreover, on T2-W images, a hyper-intense spot was found without obvious damage. In the animals of the PBS group, no sign of cerebral injury such as cyst formation, edema, or hemorrhage was observed (Figure 3A).

\section{Histopathology}

To evaluate the $\mathrm{PKH}_{67}^{+}$cells tropism to the glioma mass, serial cryo-sections were evaluated using a fluorescent microscope. Clearly, the images showed the tumor area $\left(\mathrm{U} 87-\mathrm{PKH}^{+}{ }_{26}\right)$ in all the tumor-bearing groups (Figure 3B, a-c). In BMS-treated rats, BMS- $\mathrm{PKH}_{67}^{+}$cells depicted an extensive tropism into the glioma mass and tissue cryo-sections showed no BMS$\mathrm{PKH}^{+}{ }_{67}$ migrating out of the glioma mass. Dual Hoechst ${ }^{+}$and $\mathrm{PKH}_{67}^{+}$cells were observed exclusively within the brain of BMS-treated rats. Moreover, by more careful analysis of serial cryo-sections, no BMS- $\mathrm{PKH}_{67}^{+}$was detected in normal brain tissue or in the contralateral hemisphere of BMS-treated rats (Figure 3B, d-g).

Analysis of images related to OEC-treated animals indicated migration of OEC- $\mathrm{PKH}^{+}{ }_{67}$ cells toward tumor mass such as BMS- $\mathrm{PKH}_{67}^{+}$. Serial cryo-sections of the OEC-treated animals revealed that OECs have substantial migration towards tumor tissue. Images suggested that many OEC cells were resettled in glioma tissue as compared to the uninvolved brain (Figure $3 \mathrm{~B}, \mathrm{~h}-\mathrm{k})$. Cell tracer findings indicated that there were larger numbers ( 100 cells per section) of BMS cells in the tumor area of the BMS-treated rats compared with OECs-treated rats ( 76 cells per section).

In this research, $\mathrm{PKH}_{67}^{+}$cells were infused initially via the tail vein where the results indicated the lack of these cells in the tumor tissue. Results (data not shown) showed that many $\mathrm{PKH}^{+}{ }_{67}$ cells resettled in the lung, spleen, and liver after tail vein injection. These results highlighted the inability of tail vein transplantation of stem cells and suggested that other methods of delivery should be considered.

Intra-carotid and intracardiac methods were therefore studied. $\mathrm{PKH}_{67}^{+}$cells were infused into the rats via the left ventricle and after the intraventricular injection the numbers of $\mathrm{PKH}_{67}^{+}$cells were significantly increased in the tumor tissue. Moreover, our results clearly showed that intraventricular delivery of cells led to significant migration of cells towards glioma. 

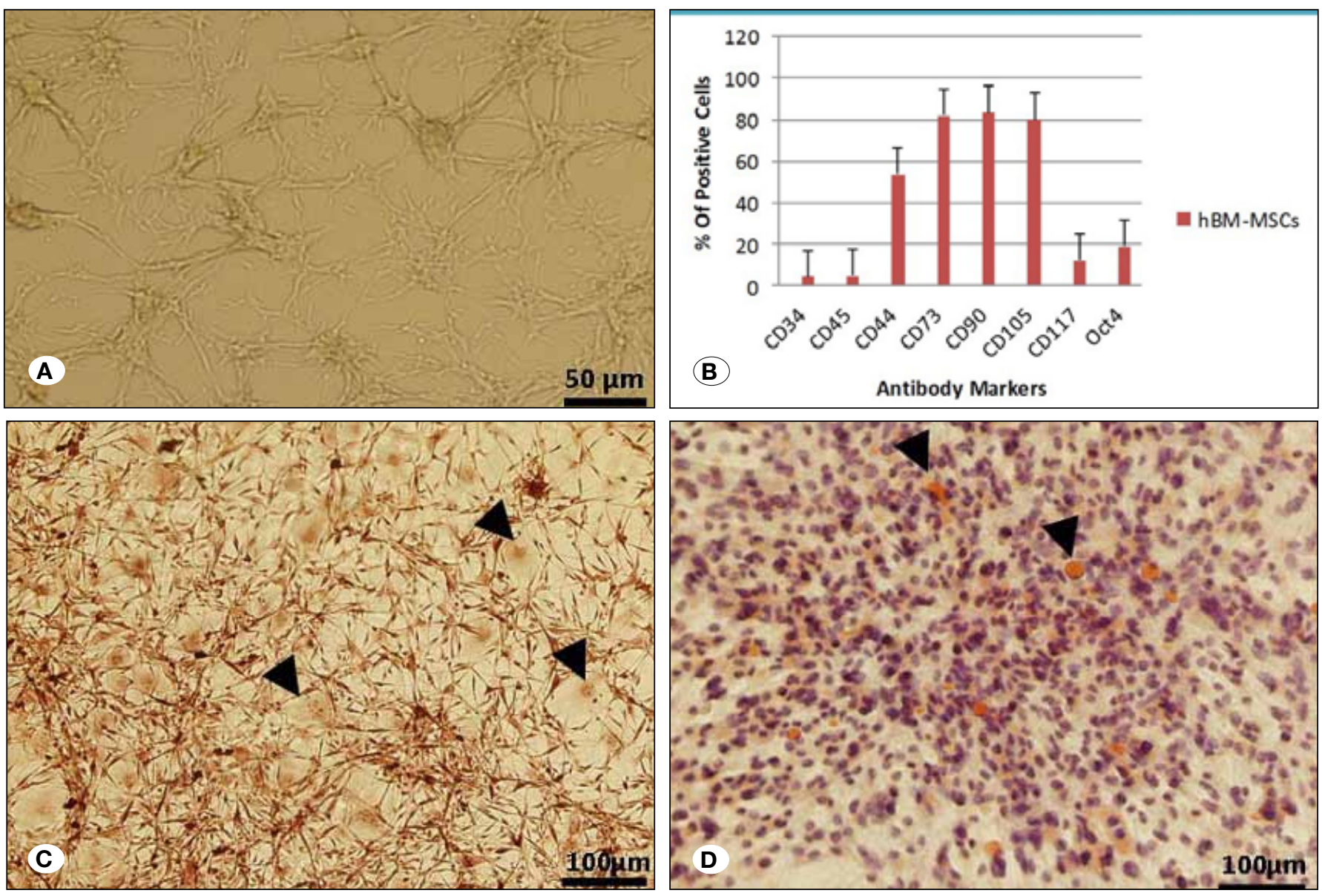

Figure 1: Characteristics of BMS cells. A) Cultured BMS cells observed as spindle-shaped cells. B) Flow cytometry analysis of BMS cells. C) Alizarin red staining, displayed $\mathrm{Ca}^{2+}$ aggregation in the extracellular matrix of induced cells (black arrowhead). D) Oil red staining exhibited lipid droplets in the cytoplasm of the induced cells (black arrowhead).

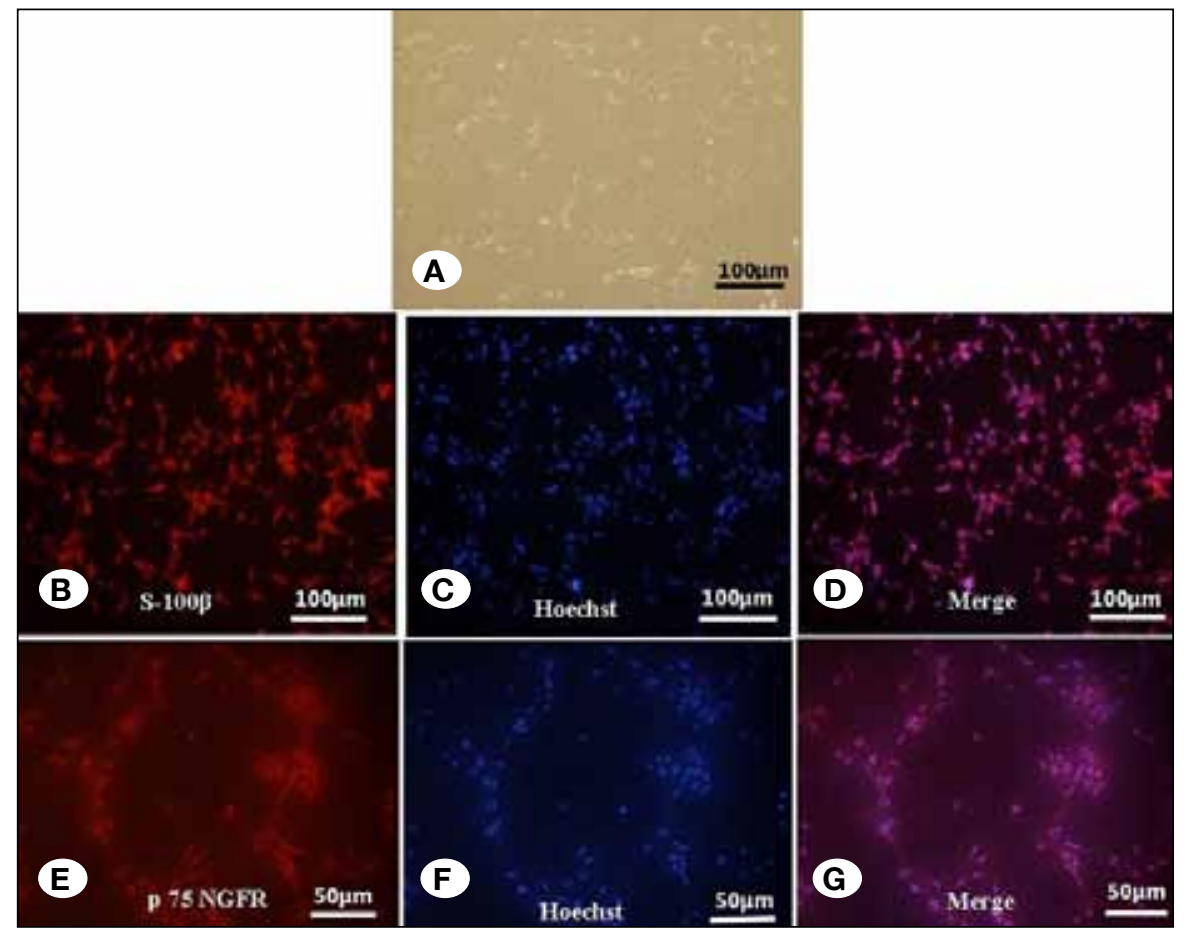

Figure 2: Characteristics of OECs.

A) Cultured OECs observed as spindleshaped cells with long processes.

B-D) Immunostaining of OECS by S100ß.

E-G) Immunostaining of OECS by p75. 
The intra-carotid route was another method that was tested. However, under intra-carotid injection, $\mathrm{PKH}^{+}{ }_{67}$ cells exhibited high migration and homing towards the tumor. However, during the intra-carotid procedure, the rate of animal death was very high. Due to this mortality rate, the intraventricular route was chosen as it was a safe and feasible method for cell delivery compared with the intra-carotid procedure.

H\&E images related to tumor-bearing animals showed that glioma tissues were strongly stained with hematoxylin compared with the normal tissue. Neoplastic properties such as mitotic division, neoangiogenesis, and migration of cancerous cells were observed in tumor-bearing rats. Interestingly, in BMSC-treated rats, not only did BMS cells led to strongly U87 cells migration towards the normal brain parenchyma but also caused formation of metastatic masses. However, no signs of metastasis were seen in the tumor group. Also, H\&E sections showed that the presence of OECs led to the reduction of tumor cell migration in the OEC-treated rats whereas, migration of U87 cells into tumor-surrounding tissues was detected in the tumor group (Figure $4 \mathrm{~A}$ ).

For determination of neovascularization, ten $\mathrm{H} \& \mathrm{E}$ sections were randomly investigated, and neoangiogenesis was counted with 200 magnification. The H\&E findings of the BMSCtreated animals showed that numerous neovascularization areas were formed compared with other groups. This increase of neovascularization indicated a significant difference with
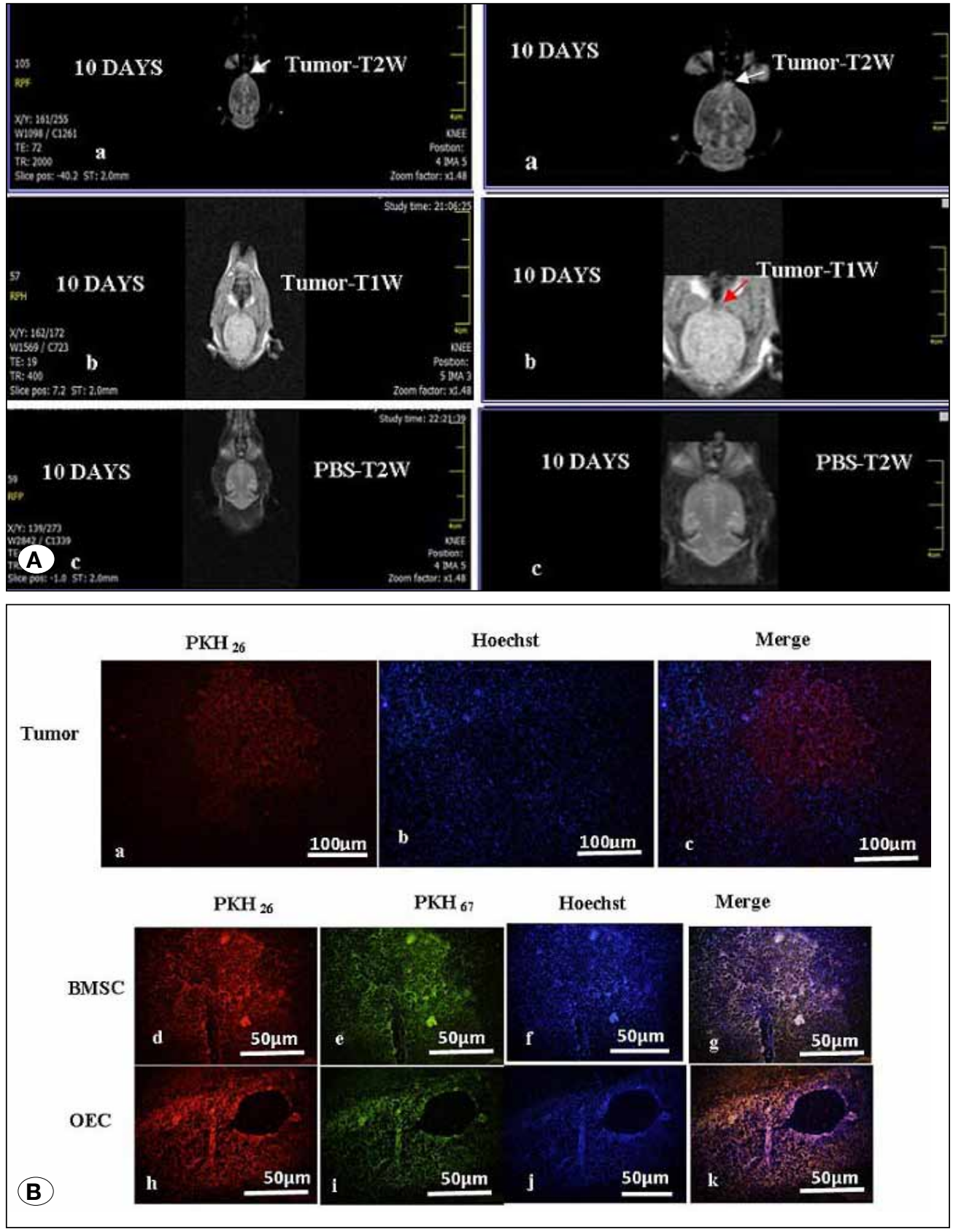

Figure 3:

\section{A: MRI of groups.}

a, b) The magnetic resonance images of tumor groups (white and red arrow). c) The magnetic resonance images of PBS group. B: Frozen sections of tumoral tissues were shown in the glioma-bearing animals.

a) Frozen section for tracking $\mathrm{PKH}^{+}{ }_{26}$ tumor cells. b) Frozen section counterstained with Hoechst. c) Merged images for detection of area of tumor. d) Frozen sections of the BMS group for tracking $\mathrm{PKH}^{+}{ }_{26}$ cells. e) Frozen section for tracking $\mathrm{PKH}_{67}^{+} \mathrm{BMS}$ cells. f) Frozen section counterstained with Hoechst. g) Merged images for detection of $\mathrm{PKH}_{67}^{+} \mathrm{BMS}$ cells. h-k) Frozen section of the OEC group revealed extensive migration of $\mathrm{PKH}_{67}^{+}-\mathrm{OECs}$ toward the tumor mass. 
tumor and OEC-treated rats. While, findings related to OECtreated rats suggested that the rate of angiogenesis was decreased compared with the tumor group, no significant difference was found between the OEC and tumor groups (Figures 4A, B).

\section{Immunohistochemistry}

The findings of IHC analysis depicted that Ki-67 expression was vastly different among experimental groups. Positive cells were strongly expressed in BMSC-treated rats but there was no statistical difference with the tumor group. However, the presence of OECs reduced the levels of Ki-67 in the animals. The OECs-treated rats showed fainter immunostaining than the tumor group although there was no statistical difference (Figure 5A-C and Figure 6A).

The results of endothelial-specific CD31 demonstrated that the levels of CD31 within the tumors of BMSC-treated rats were expressed in a significantly higher manner than the tumor-bearing animals. Less CD31 immunoreactivity was detected in the tumor mass of the OEC group. However, the results showed no significant difference between the OEC and tumor groups (Figure 5D-F and Figure 6A).

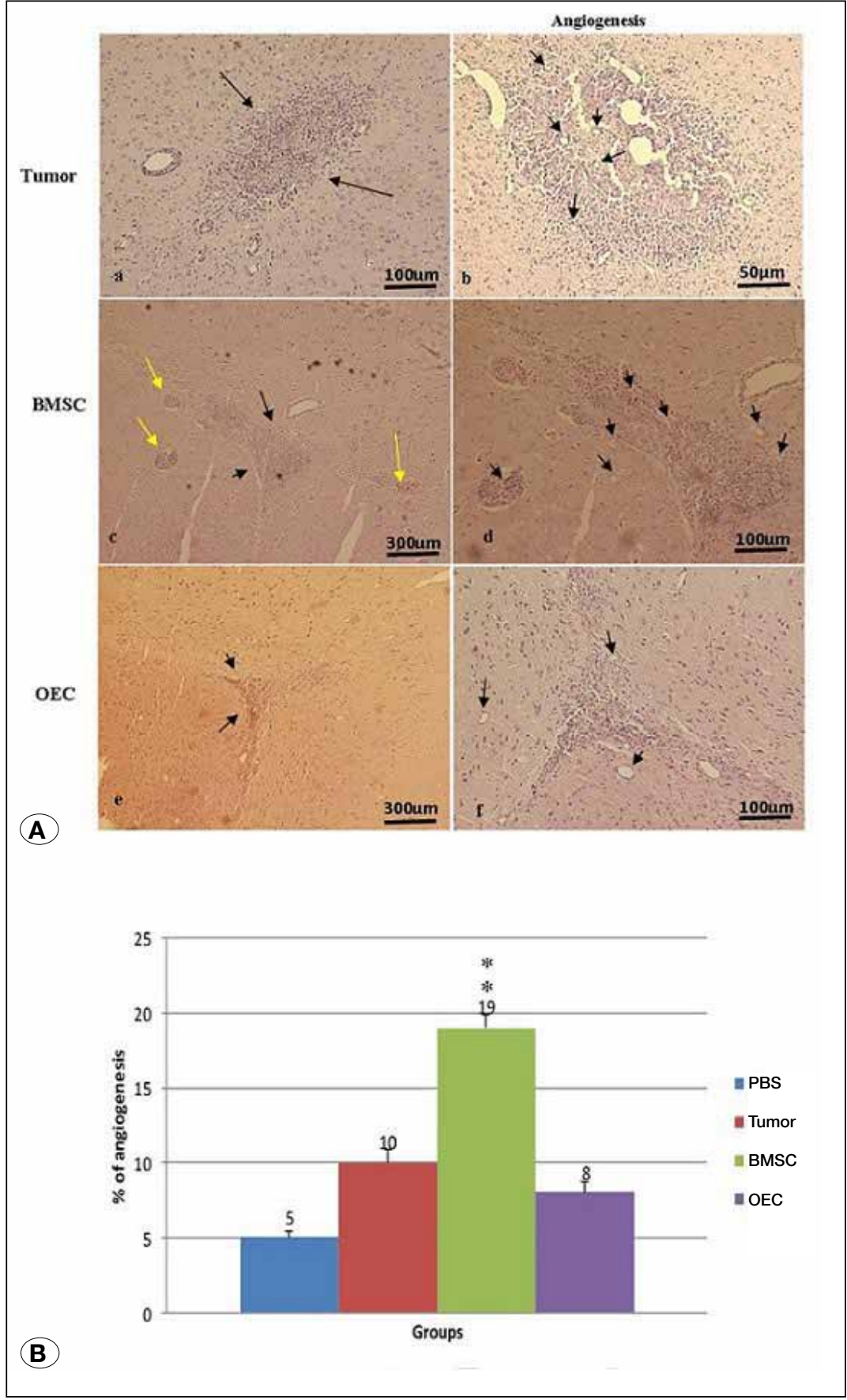

Figure 4:

A: H\&E sections of groups.

a) Site of tumor implantation (black arrow). c) The area of tumor in the BMSC group (black arrow) and metastatic masses of tumor in the BMSC group (yellow arrow). e) The area of tumor in the OEC group (black arrow). b) Angiogenesis in tumor mass in the tumor group (black arrow). d) Angiogenesis in tumor mass in the BMSC group (black arrow). e) Angiogenesis in tumor mass in the OEC group (black arrow).

B: Angiogenesis analysis in groups. Angiogenesis analysis between groups. Data are expressed as mean \pm SEM. ${ }^{*}: p<0.05,{ }^{*}: p<0.01$. 
IHC staining of GFAP showed poor expression in the tumor group; also, the formation of a glial edge at the tumor periphery was observed. Our findings illustrated that levels of GFAP were almost the same in BMSC-treated rats compared with the tumor group. On the contrary, not only was GFAP widely expressed inthe OEC group, it also depicted a significant difference with tumor-bearing rats (Figure 5G-I and Figure 6A).

Our findings suggested that the protein level of Nestin in the OEC-treated rats was markedly upregulated as compared with other groups, which in turn represented a significant difference with other experimental groups (Figure 6A). The results of Nestin immunostaining showed no significant difference between the tumor and BMSC groups (Figure $5 \mathrm{~J}-\mathrm{L}$ and Figure 6A).

\section{Volume}

To assess the therapeutic efficacy of the $\mathrm{PKH}^{+}{ }_{67}$ cell, the tumor volume was determined. The mean tumor volumes in the OEC, BMSC, and tumor groups were $3.23 \mathrm{~mm}^{3}, 5.07 \mathrm{~mm}^{3}$, and $3.26 \mathrm{~mm}^{3}$, respectively. The tumor volume analysis revealed a decrease in tumor size in rats treated with OEC. However, there was no significant difference in tumor volume between the groups treated with OECs and the tumor. In contrast, tumor volume was significantly higher in the BMSC group. Statistical analysis showed a significant growth in glioma mass in the BMSC group compared with the other experimental groups (Figure 6B).

\section{DISCUSSION}

This study focused on demonstrating the tropism of OECs and BMSC to glioma and generally the effects of these cells on glioma behavior in an animal model.

OECs were successfully obtained from the human olfactory bulb, suggesting that the ensheathing layers of the human olfactory bulb are a rich source of neural stem cells. The ICC results confirmed both the origin and purity of OECs in line with previous reports (17). Flow cytometry results of BMS cells and their ability to differentiate into adipogenic and osteogenic line confirmed the origin and potential of the BMS cells (22).

In the present study, not only the migratory ability, but also the direction of the invasion of BMS cells and OECs towards the glioma mass have been illustrated. BMS cells suggested

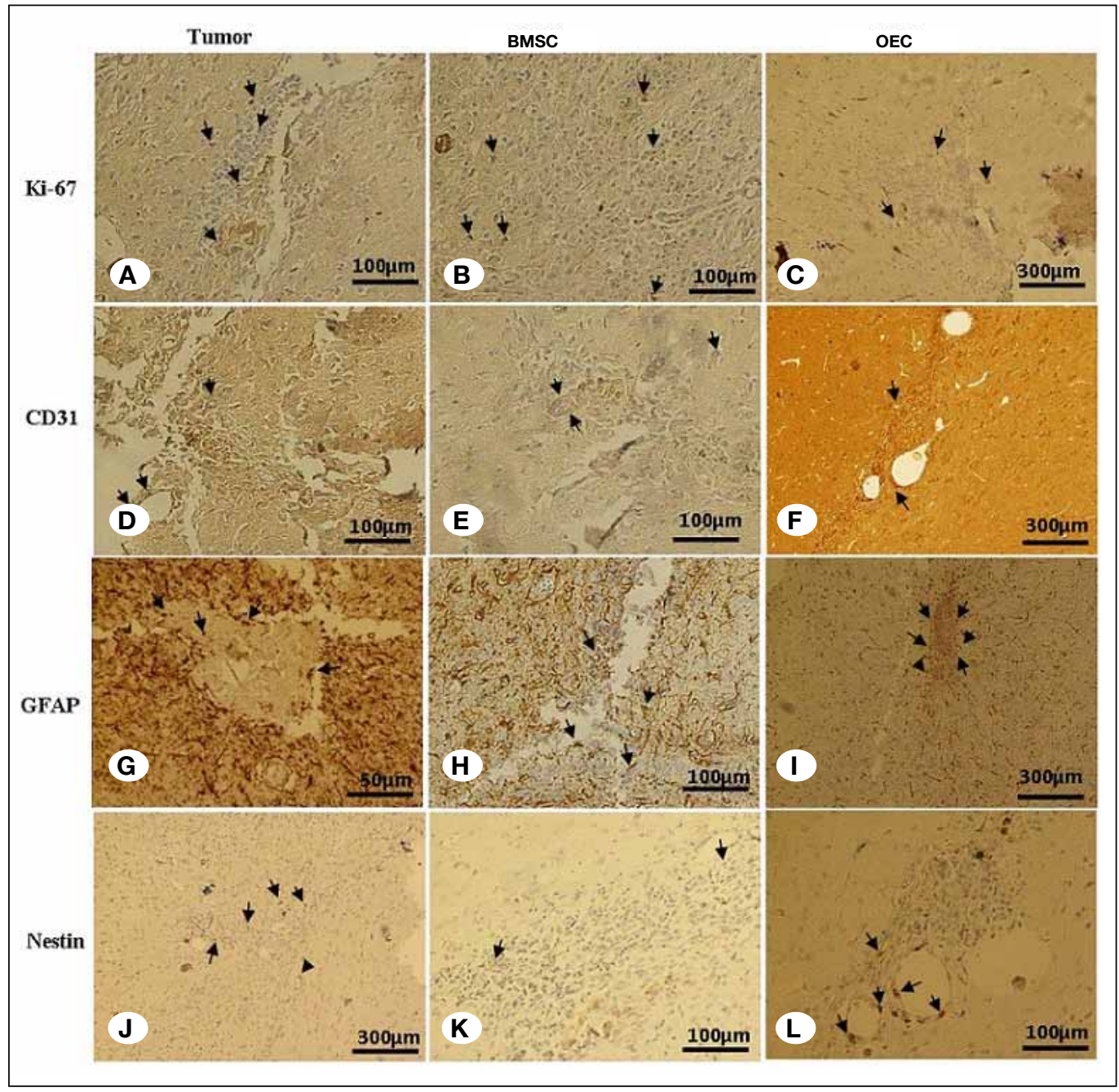

Figure 5: Immunostaining of groups.

A) Ki-67 positive tumor cell in the tumor area (black arrows). B) Ki-67 positive tumor cell in the tumor area in the BMSC group (black arrows). C) Ki-67 positive tumor cell in the tumor area in the OEC group (black arrows). D) CD-31 positive cells in tumor area in the tumor group (black arrows). E) Positive cells around the tumor area in the BMSC group (black arrows). F) CD31 positive cells in the tumor area in the OEC group (black arrows). G) GFAP positive tumor cells in the tumor tissue. H) GFAP positive cells in the tumor area in the BMSC group (black arrow). I) GFAP positive cells in the tumor area in the OEC group (black arrow). J) Nestin positive tumor cell in the tumor area (black arrows). K) Nestin positive cell in the tumor area in the BMSC group (black arrows). L) Nestin positive cell in the tumor area in the OEC group (black arrows). 
an active movement into the glioma microenvironment. Therefore, the findings of some researchers who reported the extensive tropism of MSCs tumor and intracranial injuries could be confirmed $(16,24,30)$. Furthermore, excellent and directed migratory ability of human OECs towards the glioma were observed. Our findings keep in line with the data reported about the OECs ability to migrate toward pathological areas such as brain and spinal cord injuries (14). The fact that both OECs and BMS cells widely moved into the glioma tissue shows that these cells have a strong inherent and unique ability in migration and homing towards tumor.

Some of the studies indicated that the tropism of stem cells towards the tumor may be mediated by the tumor microenvironment. The tumor milieu provides some attractive chemical material such as growth factors, extracellular matrix molecules, and chemokines $(6,9,30)$. Whereas, according to our findings, the tumor microenvironment merely could not be the cause of migration and homing of these cells. We previously illustrated that human umbilical cord mesenchymal cells showed less ability to migrate towards glioma compared with these cells (1). Thus, it seems that the extensive ability of BMS cells and OECs in localizing to glioma was a specific feature of these cells, and it could not be a function of all human cells. It is also unlikely that the migration and homing of these cells were the result of a species-specific (human stem cells-human U87 cell) tropism. Taking these findings together, the tumor microenvironment and species-specific tropism may not be the only key factors in migration and homing of the cell towards a tumor mass. The inherent nature of the cell may also play an important role in the migration mechanisms of a cell.

An important aspect of this study is the migration and homing of OECs and BMS cells towards the glioma, which supports the hypothesis that cell-based therapy could lead

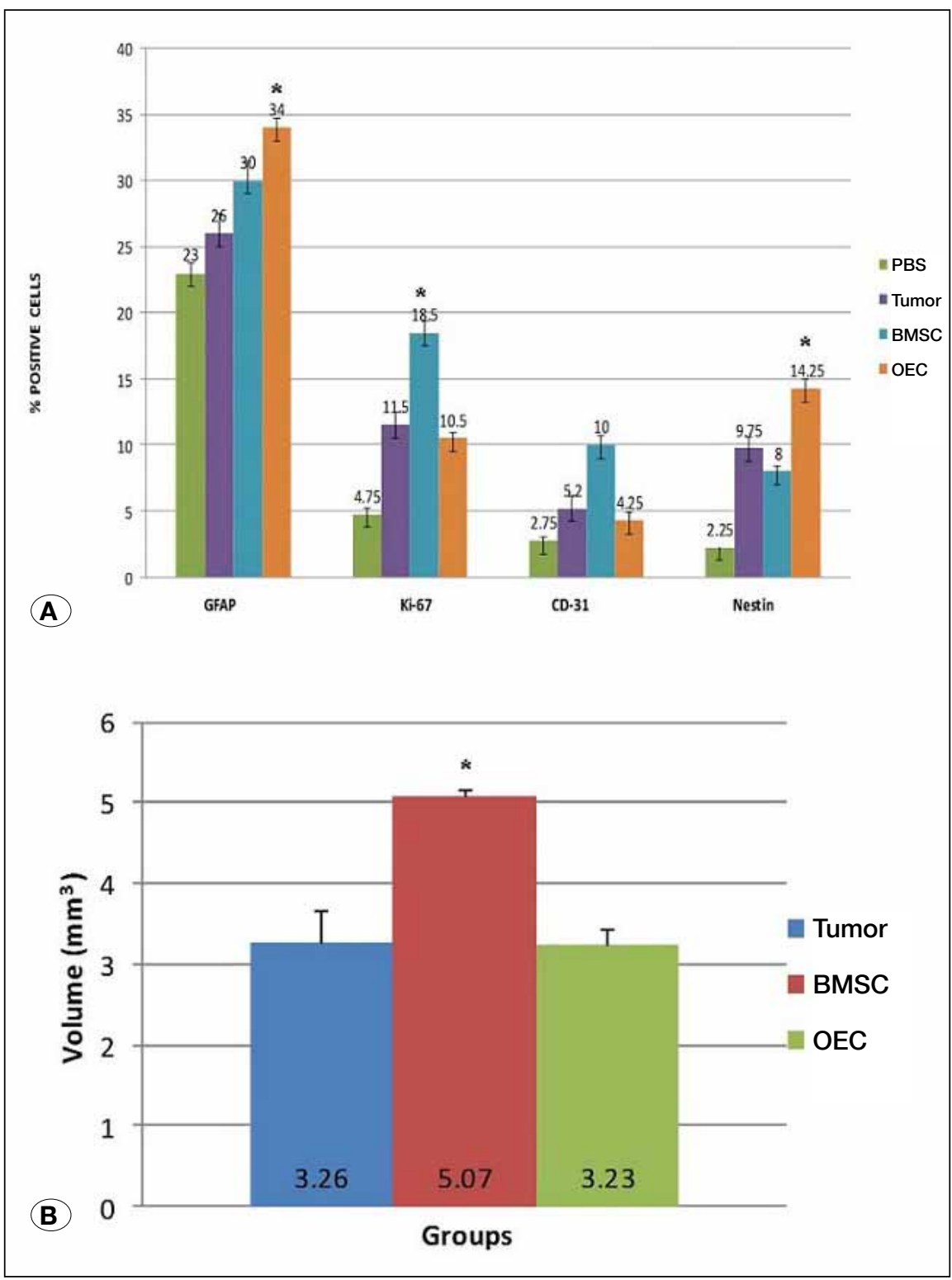

Figure 6:

A) Immunostaining analysis of groups. Data are expressed as mean \pm SEM. *: $p<0.05$

B) Volume analysis of tumor-bearing group.

Data are expressed as mean \pm SEM. *: $p<0.05$. 
to a valuable improvement of glioma therapy. Most anticancer agents cannot achieve therapeutic concentrations in the brain because, there are physiologic barriers including the BBB and the high intratumor pressure (26). Therefore, only small particles such as stem cells can penetrate the BBB and reach the tumor. As a result, these cells can be efficient carriers for anti-cancer therapeutic agents' delivery to target tissue, a critical feature of achieving therapeutic efficacy. Moreover, these cells have shown a strong chemotactic response to injuries $(14,41)$. Thus, OECs and BMS cells may be used as tumor-selective targeting carriers for the delivery of anti-cancer agents and cytotoxic genes toward the tumor. The aforementioned findings suggest that these cells could function like "Trojan horses" for the delivery of therapeutic agents to the glioma in clinical trials.

In this study, histological slides of the brain revealed histologic features such as pleomorphism, mitotic activity, and nuclear atypia in the tumor and BMS groups. By $\mathrm{IHC}$ analysis and measurement of tumor volume, an association of grafted BMS cells with outgrowing glioma mass was indicated. The findings showed that BMS cells play a key role in tumor neovascularization and glioma progression. Evidence also indicates that grafted MSCs directly support the tumor vasculature and growth of tumors $(28,39)$.

Another contribution of grafted BMS cells to tumor growth occurs through the accelerated proliferation of glioma cells. Here, it has been demonstrated that BMS cells increase the Ki-67 labeling index in BMSC-treated rats. These data are in agreement with findings from Spaeth et al.(38) which reported MSCs enhance proliferation of breast cancer cells. Furthermore, the outcome of this research illustrated that BMS cells enhance the metastatic potency of tumor. This finding suggests that grafted BMS cells may maintain the proliferative potential of tumor cells, and retain the malignant process. Recently, studies reported that MSCs promote cancer growth and metastasis $(20,29)$. However, MSC cancer-suppressing effects have only been observed in a few reports $(33,34)$; and most studies reported that migration of MSC leads to angiogenesis and tumor development $(27,32)$. Moreover, extensive tropism of BMS cells to tumor was observed, which may be due to the BMS cells secreting a variety of substances such as stem cell factor, interleukins, and colony-stimulating factor- I $(5,8)$.

In the present work, the results suggested that the presence of OECs leads to decrease of glioma tissue growth. Furthermore, the high expression of GFAP in tumor tissue was shown in OEC-treated rats, which confirmed both the migration and homing of OECs into glioma as OECs are GFAP and Nestin positive cells $(31,40)$.

These results illustrate that the interactions between OECs and tumor cells down-regulate invasion, tumor growth, and metastasis as a mechanism of the anti-glioma effect. This can also be due to substrates and neurotrophic factors being provided by OECs that contribute to neurons regeneration and normal neuron survival. It was also observed that OECs provide least adverse reaction in the brain after transplantation, and reports have also confirmed that OECs have non-tumorigenic behavior $(13,16)$. Thus, the multifunctional capacity of OECs has numerous positive consequences. First, OECs have a manifest tropism to the glioma mass. Second, OECs can be inherently safer than other molecular approaches that target tumor tissue, and these cells are unlikely to produce systemic toxicity. Third, OECs can be obtained from the patient. Finally, OECs can be modified in vitro to provide unique potencies and properties for GBM therapy.

With this information, future studies on migration and homing mechanisms of OECs and BMS cells towards glioma should be performed. Identification of the migratory mechanisms and the behavior of cells may lead to the application of these cells in clinical trials for the treatment of glioma.

\section{- CONCLUSION}

In this study, OECs caused decrease of mitotic activity, as well as angiogenesis. OECs and BMS cells showed the capacity to integrate into human glioma. Moreover, these cells may be cellular carriers, which are universally applicable like "Trojan horses" for the delivery of cytotoxic genes and therapeutic agents for glioma.

\section{- REFERENCES}

1. Abdi Z, Eskandary H, Nematollahi-Mahani S: Human umbilical cord matrix-derived stem cells show tropism towards the human glioma microenvironment. Int J Stem Cell Res Transplant 4:146-145, 2016

2. Aboody KS, Brown A, Rainov NG, Bower KA, Liu S, Yang W, Small JE, Herrlinger U, Ourednik V, Black PM: Neural stem cells display extensive tropism for pathology in adult brain: Evidence from intracranial gliomas. Proc Natl Acad Sci USA 97: 12846-12851, 2000

3. Adamson C, Kanu OO, Mehta Al, Di C, Lin N, Mattox AK, Bigner DD: Glioblastoma multiforme: A review of where we have been and where we are going. Expert Opin Investig Drugs 18:1061-1083, 2009

4. Aghaee-afshar M, Rezazadehkermani M, Asadi A, Malekpourafshar R, Shahesmaeili A, Nematollahi-mahani SN: Potential of human umbilical cord matrix and rabbit bone marrowderived mesenchymal stem cells in repair of surgically incised rabbit external anal sphincter. Dis Colon Rectum 52:17531761, 2009

5. Azizi SA, Stokes D, Augelli BJ, DiGirolamo C, Prockop DJ: Engraftment and migration of human bone marrow stromal cells implanted in the brains of albino rats-similarities to astrocyte grafts. Proc Natl Acad Sci USA 95: 3908-3913, 1998

6. Bissell MJ, Radisky D: Putting tumours in context. Nat Rev Cancer 1: 46-54, 2001

7. Black PM: Brain tumor. Part 2. N Engl J Med 324:1555-1564, 1991

8. Colter DC, Class R, DiGirolamo CM, Prockop DJ: Rapid expansion of recycling stem cells in cultures of plasticadherent cells from human bone marrow. Proc Natl Acad Sci USA 97: 3213-3218, 2000

9. Coussens LM, Werb Z: Inflammation and cancer. Nature 420 : 860-867, 2002

10. Dirks PB: Glioma migration: Clues from the biology of neural progenitor cells and embryonic CNS cell migration. J Neurooncol 53: 203-212, 2001 
11. Dwyer RM, Ryan J, Havelin RJ, Morris JC, Miller BW, Liu Z, Flavin R, O'Flatharta C, Foley MJ, Barrett $\mathrm{HH}$ : Mesenchymal stem cell-mediated delivery of the sodium iodide symporter supports radionuclide imaging and treatment of breast cancer. Stem Cells 29:1149-1157, 2011

12. Ehtesham M, Kabos P, Gutierrez MA, Chung NH, Griffith TS, Black KL, John SY: Induction of glioblastoma apoptosis using neural stem cell-mediated delivery of tumor necrosis factorrelated apoptosis-inducing ligand. Cancer Res 62:7170-7174, 2002

13. Escada PA, Lima C, da Silva JM: The human olfactory mucosa. Eur Arch Otorhinolaryngol 266:1675-1680, 2009

14. Féron F, Perry C, Cochrane J, Licina P, Nowitzke A, Urquhart S, Geraghty T, Mackay-Sim A: Autologous olfactory ensheathing cell transplantation in human spinal cord injury. Brain 128: 2951-2960, 2005

15. Hall B, Dembinski J, Sasser AK, Studeny M, Andreeff M, Marini F: Mesenchymal stem cells in cancer: Tumor-associated fibroblasts and cell-based delivery vehicles. Int J Hematol 86: 8-16, 2007

16. Harting MT, Baumgartner JE, Worth LL, Ewing-Cobbs L, Gee AP, Day MC, Cox CS Jr: Cell therapies for traumatic brain injury. Neurosurg Focus 24: E18, 2008

17. Hashemi M, Fallah A, Aghayan HR, Arjmand B, Yazdani N, Verdi J, Ghodsi SM, Miri SM, Hadjighassem M: A new approach in gene therapy of glioblastoma multiforme: Human olfactory ensheathing cells as a novel carrier for suicide gene delivery. Mol Neurobiol 1-11, 2015

18. Huang $\mathrm{H}$, Chen L, Wang $\mathrm{H}$, Xi H, Gou C, Zhang J, Zhang F, Liu Y: Safety of fetal olfactory ensheathing cell transplantation in patients with chronic spinal cord injury. A 38-month followup with MRI. Zhongguo Xiu Fu Chong Jian Wai Ke Za Zhi 20: 439-443, 2006 (In Chinese)

19. Jansen $M$, de Witt Hamer PC, Witmer AN, Troost $D$, van Noorden CJ: Current perspectives on antiangiogenesis strategies in the treatment of malignant gliomas. Brain Res Rev 45: 143-163, 2004

20. Karnoub AE, Dash AB, Vo AP, Sullivan A, Brooks MW, Bell GW, Richardson AL, Polyak K, Tubo R, Weinberg RA: Mesenchymal stem cells within tumour stroma promote breast cancer metastasis. Nature 449: 557-563, 2007

21. Kaviani M, Ezzatabadipour M, Nematollahi-Mahani SN, Salehinejad P, Mohammadi M, Kalantar SM, Motamedi B: Evaluation of gametogenic potential of vitrified human umbilical cord Wharton's jelly-derived mesenchymal cells. Cytotherapy 16: 203-212, 2014

22. Kern S, Eichler H, Stoeve J, Klüter H, Bieback K: Comparative analysis of mesenchymal stem cells from bone marrow, umbilical cord blood, or adipose tissue. Stem Cells 24:12941301, 2006

23. Klopp AH, Spaeth EL, Dembinski JL, Woodward WA, Munshi A, Meyn RE, Cox JD, Andreeff M, Marini FC: Tumor irradiation increases the recruitment of circulating mesenchymal stem cells into the tumor microenvironment. Cancer Res 67:1168711695, 2007

24. Kucerova L, Matuskova M, Hlubinova K, Altanerova V, Altaner C: Tumor cell behaviour modulation by mesenchymal stromal cells. Mol Cancer 9: 129, 2010

25. Lacroix M, Abi-Said D, Fourney DR, Gokaslan ZL, Shi W, DeMonte F, Lang FF, McCutcheon IE, Hassenbusch SJ, Holland E: A multivariate analysis of 416 patients with glioblastoma multiforme: Prognosis, extent of resection, and survival. J Neurosurg 95:190-198, 2001
26. Laquintana V, Trapani A, Denora N, Wang F, Gallo JM, Trapani G: New strategies to deliver anticancer drugs to brain tumors. Exp Opin Drug Deliv 6:1017-1032, 2009

27. Li L, Tian H, Yue W, Zhu F, Li S, Li W: Human mesenchymal stem cells play a dual role on tumor cell growth in vitro and in vivo. J Cell Physiol 226:1860-1867, 2011

28. Lin G, Yang R, Banie L, Wang G, Ning H, Li LC, Lue TF, Lin CS: Effects of transplantation of adipose tissue-derived stem cells on prostate tumor. Prostate 70:1066-1073, 2010

29. Muehlberg FL, Song YH, Krohn A, Pinilla SP, Droll LH, Leng $X$, Seidensticker M, Ricke J, Altman AM, Devarajan E: Tissueresident stem cells promote breast cancer growth and metastasis. Carcinogenesis 30: 589-597, 2009

30. Nakamura K, Ito Y, Kawano Y, Kurozumi K, Kobune M, Tsuda H, Bizen A, Honmou O, Niitsu Y, Hamada H: Antitumor effect of genetically engineered mesenchymal stem cells in a rat glioma model. Gene Ther 11: 1155-1164, 2004

31. Ni WF, Yin LH, Lu J, Xu HZ, Chi YL, Wu JB, Zhang N: In vitro neural differentiation of bone marrow stromal cells induced by cocultured olfactory ensheathing cells. Neurosci Lett 475: 99103, 2010

32. Prantl L, Muehlberg F, Navone NM, Song YH, Vykoukal J, Logothetis CJ, Alt EU: Adipose tissue-derived stem cells promote prostate tumor growth. Prostate 70:1709-1715, 2010

33. Qiao L, Xu Z, Zhao T, Zhao Z, Shi M, Zhao RC, Ye L, Zhang X: Suppression of tumorigenesis by human mesenchymal stem cells in a hepatoma model. Cell Res 18:500-507, 2008

34. Qiao L, Zhao TJ, Wang FZ, Shan CL, Ye LH, Zhang XD: NF-kB downregulation may be involved the depression of tumor cell proliferation mediated by human mesenchymal stem cells. Acta Pharmacol Sin 29:333-340, 2008

35. Ramón-Cueto A, Avila J: Olfactory ensheathing glia: Properties and function. Brain Res Bull 46: 175-187, 1998

36. Salehinejad P, Alitheen NB, Ali AM, Omar AR, Moshrefi M, Motamedi B, Nematollahi-mahani SN: Neural differentiation of human umbilical cord matrix-derived mesenchymal cells under special culture conditions. Cytotechnology 67:449-460, 2015

37. Seyedi F, Farsinejad A, Moshrefi M, Nematollahi-Mahani SN: In vitro evaluation of different protocols for the induction of mesenchymal stem cells to insulin-producing cells. In Vitro Cell Dev Biol Anim 51: 866-878, 2015

38. Spaeth EL, Dembinski JL, Sasser AK, Watson K, Klopp A, Hall $B$, Andreeff M, Marini F: Mesenchymal stem cell transition to tumor-associated fibroblasts contributes to fibrovascular network expansion and tumor progression. PloS One 4: e4992, 2009

39. Sun B, Zhang S, Ni C, Zhang D, Liu Y, Zhang W, Zhao X, Zhao $\mathrm{C}$, Shi M: Correlation between melanoma angiogenesis and the mesenchymal stem cells and endothelial progenitor cells derived from bone marrow. Stem Cells Dev 14: 292-298, 2005

40. Wang B, Han J, Gao Y, Xiao Z, Chen B, Wang X, Zhao W, Dai $\mathrm{J}$ : The differentiation of rat adipose-derived stem cells into OEC-like cells on collagen scaffolds by co-culturing with OECs. Neurosci Lett 421: 191-196, 2007

41. Wise AF, Williams TM, Kiewiet MB, Payne NL, Siatskas C, Samuel CS, Ricardo SD: Human mesenchymal stem cells alter macrophage phenotype and promote regeneration via homing to the kidney following ischemia-reperfusion injury. Am J Physiol Renal Physiol 306: F1222-F1235, 2014 